\title{
ESPECIAL 60 ANOS DA RAE: DE ESTRELA SOLITÁRIA NO PASSADO AOS DESAFIOS FUTUROS
}

\author{
Special issue 60 years of RAE: From a solitary star in the past to future challenges \\ Especial 60 años de RAE: De estrella solitaria en el pasado a los desafíos futuros
}

Maria José Tonelli ${ }^{1}$ | maria.jose.tonelli@fgv.br | ORCID: 00oo-0oo2-6585-1493

Felipe Zambaldi ${ }^{1}$ | felipe.zambaldi@fgv.br | ORCID: 00oo-0oo2-5378-6444

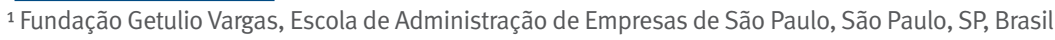

\begin{abstract}
RESUMO
Este texto apresenta os artigos convidados para esta edição especial de comemoração dos 60 anos da Revista, com o objetivo de refletir sobre o passado, o presente e o futuro da RAE-Revista de Administração de Empresas e das revistas científicas brasileiras em Administração. Apresenta-se, em primeiro lugar, o papel histórico da Revista na construção da academia brasileira em Administração, bem como seu impacto em várias gerações de pesquisadoras e pesquisadores no País. Num segundo momento, são abordados os principais problemas enfrentados na RAE e seus desafios futuros que podem, eventualmente, ser úteis para os demais periódicos brasileiros no campo da Administração. Conclui-se que a redução das desigualdades entre os periódicos nacionais e internacionais pode ser encampada como uma bandeira da RAE e de periódicos brasileiros, valendo-se de ventos favoráveis como os Objetivos de Desenvolvimento Sustentável da Organização das Nações Unidas (ONU), o movimento Declaration on Research Assessment (DORA) e a potencialidade de avaliação do impacto social das instituições e seus programas por parte de entidades acreditadoras. Mas contar com que esses ventos favoráveis façam o trabalho sozinhos seria uma ilusão, portanto há um longo trabalho de protagonismo pela frente.
\end{abstract}

PALAVRAS-CHAVE |RAE, história da Administração no Brasil, periódicos brasileiros em Administração, indexadores, desafios.

\begin{abstract}
The text presents the guest articles that were written for this special edition of RAE to commemorate its 6oth anniversary, the aim being to reflect on the past, the present and the future of this and of other Brazilian scientific journals in Administration. It starts by presenting the historical role of the journal in constructing Brazilian academia in Administration, and its impact on several generations of researchers in the country. The main problems being faced by RAE are then addressed, as are its future challenges, which may, possibly, be useful for other Brazilian journals in the field of Administration. The conclusion reached is that the reduction in inequality between Brazilian and international journals can be seen as a banner for RAE and other Brazilian journals that can now take advantage of favorable winds, such as the United Nations's (UN) Sustainable Development Goals, the Declaration on Research Assessment (DORA) movement, and the potential that accrediting bodies have for evaluating the social impact of institutions and their programs. But relying on these favorable winds to do the job alone would be an illusion; there is a lot of long-term work of leadership ahead.
\end{abstract}

KEYWORDS I RAE, the history of Administration in Brazil, Brazilian Administration journals, indexers, challenges.

\section{RESUMEN}

Este texto presenta los artículos invitados a esta edición especial de conmemoración del 60 aniversario de la revista, con el objetivo de reflexionar sobre el pasado, presente y futuro de la RAE y de las revistas científicas brasileñas de Administración. En primer lugar, se presenta el papel histórico de la revista en la construcción de la academia brasileña de Administración, así como su impacto en varias generaciones de investigadores del país. En un segundo momento, se abordan los principales problemas que enfrenta la RAE y sus desafíos futuros que, eventualmente, pueden ser de utilidad para los demás periódicos brasileños del campo de la Administración. Se concluye que la reducción de las desigualdades entre las revistas nacionales e internacionales puede verse como una bandera de la RAE y de las revistas brasileñas, aprovechando vientos favorables como los Objetivos de Desarrollo Sostenible de la Naciones Unidas (ONU), el movimiento Declaration on Research Assessment (DORA) y el potencial de evaluación del impacto social de las instituciones y sus programas por las entidades acreditadoras. Pero contar con que estos vientos favorables hagan el trabajo solos sería una ilusión; por lo tanto, queda un largo trabajo de protagonismo por delante.

PALABRAS CLAVE I RAE, historia de la Administración en Brasil, periódicos brasileños en Administración, indexadores, desafíos. 


\section{INTRODUÇÃO}

Neste ano de 2021, período pandêmico que provoca reflexões de toda sorte, a RAE-Revista de Administração de Empresas comemora 60 anos de existência. Um ano difícil para o País*, mas também um campo fértil para memórias e reflexões sobre o passado e o futuro das revistas científicas brasileiras em Administração. Parte do Sul Global, a RAE antecipou tendências, criou campos científicos na área de Administração no País como o Marketing (Tonelli, 2018) e colocou-se como um espaço para resistência, diálogos e interações. A trajetória da RAE está marcada, desde sua origem, por pioneirismo, abordagens críticas e reflexões sobre as questões sociais do País (Bertero, 2011, 2021) além de ser protagonista no ensino e na pesquisa em diversas áreas na Administração e fazer parte do "DNA" de muitos pesquisadores relevantes no campo (Paula, 2021). Mas, assim como a sociedade brasileira envelheceu, a RAE chegou aos 60, com os desafios de se reinventar.

Este texto apresenta os artigos convidados para esta edição especial de comemoração dos 60 anos da Revista, com o objetivo de refletir sobre o passado, o presente e o futuro da RAE e das revistas científicas brasileiras em Administração. A RAE é o periódico acadêmico mais longevo em Administração de Empresas no Brasil, se considerarmos que sua publicação é ininterrupta desde seu lançamento. As autoras e autores convidados para esta edição fazem parte dessa história e tratam, cada um a seu modo, criativamente, da importância da Revista no campo acadêmico em Administração no Brasil.

Ao introduzir as autoras, os autores e os artigos convidados, reflete-se, em primeiro lugar, sobre o papel histórico da Revista na construção da academia brasileira em Administração, bem como seu impacto em várias gerações de pesquisadoras e pesquisadores no País. Num segundo momento, são abordados os principais problemas enfrentados na RAE e seus desafios futuros que podem, eventualmente, ser úteis para os demais periódicos brasileiros no campo da Administração. Nessa segunda seção, discute-se a questão da internacionalização das revistas, um tópico, apesar de tudo, atual. Destaca-se que as revistas nacionais sofrem com os objetivos de internacionalização dos programas de pós-graduação que incentivam seus pesquisadores a publicarem em periódicos internacionais de alto fator de impacto. Se, de um lado, a internacionalização da produção científica permite a inserção dos pesquisadores brasileiros no Norte Global, de outro, leva ao desinteresse desses mesmos pesquisadores pelas publicações em revistas nacionais. 0 futuro das revistas nacionais está em perigo, dadas as demandas contraditórias que pesquisadores e programas de pós-graduação precisam enfrentar: de um lado, contribuírem com soluções para problemas locais urgentes e, de outro, estarem inseridos na comunidade internacional. Nesse sentido, é necessário que as revistas se posicionem diante das demandas crescentes por pesquisas que atendam aos Objetivos de Desenvolvimento Sustentável da ONU (2021), de novas demandas de órgãos regulatórios nacionais e de acreditadoras estrangeiras que agora buscam avaliar as Escolas de Negócios por seu impacto social local (EFMD Global services/ Business School Impact System, 2020).

\section{SOBRE OS ARTIGOS CONVIDADOS}

A história da RAE reflete a história do ensino e da pesquisa em Administração de Empresas no Brasil, registrada em diversos textos de Carlos Osmar Bertero, comentados a seguir. Editor-chefe da RAE em duas ocasiões, autor profícuo com mais de três dezenas de artigos publicados na Revista, Carlos Osmar Bertero também esteve pre- 
sente em várias edições comemorativas da RAE. No editorial por ocasião dos 45 anos da Revista, Bertero (2006a, p.5) trata da falta de cidadania no País, "fruto historicamente construído de uma sociedade civil débil e cujo ônus se estende aos mais diversos espaços da vida nacional”, que se contrapõe à democracia acadêmica, em que todos são igualmente considerados. Bertero (2006a, p.5) continua: “O sistema de revisão por pares é uma demonstração de humildade pela qual todo autor submete sua produção ao julgamento de colegas, estando obrigado a acatá-lo". Nada mais atual no cenário contemporâneo: a necessidade de cidadania, consideração com o esforço de uma comunidade para produzir conhecimento, apoiado na democracia da pesquisa científica, e a necessidade premente de humildade em todos os aspectos da vida social. Nessa mesma edição, Bertero (2006b, p.2) trata do papel da Revista, no cenário nacional, como uma "ousadia": "Pretendia-se ter um periódico que divulgasse um novo campo de ensino, cujos cursos de graduação haviam acabado de abrir [...]". Foi nesse contexto que a RAE criou e acompanhou o desenvolvimento de todas as áreas da Administração no País, como Operações, Marketing, Organizações e Comportamento Organizacional (Tonelli, 2018).

A ênfase em periódicos científicos começou na década de 1970, e a criação da Associação Nacional de Pós-Graduação em Administração (ANPAD), em 1976, teve um papel relevante nessa mudança de direção (Fachin, 2006). Nesse período, o País enfrentava repressão por parte do governo militar, quando as revistas da área de Ciências Sociais foram especialmente vítimas de censura. Nesse período, a RAE acolheu contribuições dessa área, ainda que tenha recebido inúmeras advertências para a não publicação de tópicos que criticassem a política econômica do governo, em especial a questão da distribuição de renda. Mas, apesar dessas restrições, vários artigos críticos foram publicados. Pode-se considerar que foram ações de resistência e a "reafirmação da crença na liberdade de expressão, indispensável à produção científica ...", afirma Bertero (2006b, p. 3). A RAUSP-Management Journal sofreu também as consequências desse período, e sua publicação foi interrompida (Tonelli, 2017). $O$ acolhimento e a publicação de artigos críticos na RAE (assim como o da própria Escola de Administração de Empresas de São Paulo) deveriam, sem dúvida, ser mais pesquisados.

No final dos anos 1970, com a expansão da produção científica, a revista incorporou o sistema de avaliação duplo-cego e, aos poucos, firmou-se como uma revista acadêmica. Mas as revistas científicas eram reduzidas e, por ocasião do aniversário de 50 anos da Revista, um novo artigo de Bertero (2011) mostra que a RAE brilhou como estrela solitária durante décadas no cenário nacional das publicações acadêmicas em Administração. Nesse artigo, Bertero (2011) trata da origem generalista da Revista e propõe que a RAE seja uma revista de Gestão, identidade essa que a revista não assumiu até hoje. E esse tema é retomado por Bertero (2021), nesta edição especial, no artigo: “Sessenta anos de RAE: Um itinerário de críticas, resistências e reinvenções”, quando o autor enfatiza que, embora a RAE seja uma revista generalista desde sua origem, por ter sido composta por um corpo editorial diverso (Valente \& Serafim, 2006), se destaca por publicar artigos nas áreas de "Organização e Estudos Organizacionais, Estratégia e Gestão de Recursos Humanos ou Pessoas”. Com o passar dos anos, ela também apresenta uma ". . crescente sofisticação metodológica .... distantes dos primeiros anos, em que era uma revista que poderíamos considerar provinciana”, afirma Bertero (2021, p.1) nesta edição, e é otimista: "Não há dúvida de que avançamos".

Carlos Osmar Bertero figura como um dos autores mais acessados na RAE, em especial, com o artigo "A evolução da análise organizacional no Brasil (1961-1993)", em parceria com Tania Margarete Mezzomo Keinert (1994), um clássico sobre a Administração à brasileira; "Algumas observações sobre a obra de G. Elton Mayo" (1968); e "A produção científica brasileira em administração na década de 2000" (2013), em parceria com Flávio Carvalho de Vasconcelos, Marcelo Pereira Binder e Thomaz Wood Jr. Mas seu artigo mais acessado, em parceria 
com Rafael Alcadipani, trata da "Guerra Fria e o ensino do management no Brasil: o caso da FGV-EAESP" (Alcadipani \& Bertero, 2012). Nesse artigo, os autores fazem uma análise da difusão do pensamento norte-americano no pós-guerra e do modelo de gestão norte-americano no País. Mas aqui cabe uma ressalva: se, de um lado, a RAE, como parte da Escola de Administração de Empresas de São Paulo da Fundação Getulio Vargas (FGV EAESP), teve um papel na difusão das ideias do pensamento norte-americano em Administração (Alcadipani \& Bertero, 2012; Tonelli, 2018), de outro, os artigos de Carlos Osmar Bertero aqui retomados mostram que a Revista difundiu, com pioneirismo, democraticamente, o pensamento brasileiro crítico em Ciências Sociais e Econômicas, bem como o pensamento europeu, como veremos nos artigos convidados de Luiz Carlos Bresser-Pereira e Jean-François Chanlat desta edição.

Luiz Carlos Bresser-Pereira é um autor presente na Revista desde o início, com mais de 30 artigos publicados ao longo destas décadas. Como Bresser-Pereira confessa, no artigo apresentado nesta edição especial, seu primeiro artigo submetido à Revista foi recusado pelo então editor da RAE, quando do lançamento da Revista, em 1961. Para aqueles que não o conhecem, vale a leitura do artigo recusado: "The rise of the middle-class and middle management in Brazil”, publicado no Journal of Inter-American Studies (1962a), essencial para a compreensão do papel dos administradores profissionais no desenvolvimento econômico do País.

Seu primeiro artigo publicado na RAE data de 1962 e trata do "Desenvolvimento econômico e o empresário”, onde o autor define o que é desenvolvimento e discute o papel dos empresários na expansão da economia, diferencia o empresário, o administrador e o capitalista, e trata da relação entre o empresário e o Estado, como "dois agentes estratégicos do desenvolvimento" (Bresser-Pereira, 1962b, p. 90). Destaca-se também a importância dos textos de Bresser-Pereira sobre a necessidade da profissionalização da Administração no País. Já em 1966, e antes de sua regularização, Bresser-Pereira afirmava a importância da profissão, em "O administrador profissional e as perspectivas da sociedade brasileira", e a definia:

A Administração é sem dúvida uma profissão, desde que é uma atividade especializada, remunerada, com objeto próprio e constitui a fonte de receita, por excelência, daqueles que a exercem. E um administrador de empresas profissional é aquele indivíduo que, sem possuir a propriedade de uma empresa, toma decisões sobre seus recursos humanos e materiais, planejando, organizando e controlando suas operações. É o homem (sic) que realiza essas funções especializadas em razão de sua competência profissional, e não por ser o proprietário da empresa ou por manter com estas relações de parentesco ou amizade. (Bresser-Pereira, 1966, p. 89)

Não é possível recuperar neste espaço todas as contribuições dessa trintena de artigos de Bresser-Pereira, tarefa que a pesquisa historiográfica em Administração no Brasil deveria revisitar. No artigo desta edição, "Depois do capitalismo, o gerencialismo democrático", Bresser-Pereira (2021, p.1) trata da decadência do modelo neoliberal nos Estados Unidos, apresenta sua classificação para as fases do capitalismo e sua tese de que o "capitalismo deixou de produzir desenvolvimento econômico e progresso humano". 0 autor propõe que, neste novo momento, ". . . a classe dos gerentes ou tecnoburocratas voltou a se fortalecer e a constituir o núcleo da nova coalisão de classes dominantes", e traz uma visão otimista para o futuro, que ele chama de "gerencialismo burocrático", num mundo pós-capitalista. 0 autor questiona: Qual a função da riqueza sem função social? Pergunta fundamental para o mundo hoje, em que novos ares nas pesquisas em Administração, com foco nos Objetivos de Desenvolvimento Sustentável da ONU e no impacto social das Escolas de Negócios, contribuem com alguma esperança. 
Como mencionado, a RAE apresenta, desde sua origem, artigos com abordagens críticas, na vertente hoje estabelecida como Critical Management Studies. Ainda que não só, a perspectiva crítica teve sua base ancorada em autores franceses, e a história do pensamento francês na construção da academia brasileira em Administração é contada por Jean-François Chanlat no artigo convidado para esta edição especial. Chanlat é um autor presente na $R A E$, assíduo palestrante em congressos acadêmicos no Brasil, em especial, no Encontro Nacional dos Programas de Pós-Graduação em Administração (EnANPAD), promovido pela ANPAD, e presença frequente em diversas Escolas de Administração em todo o País. Conforme o autor recupera no seu artigo, "Influência do pensamento de língua francesa na academia brasileira de Administração: um olhar Franco-quebequense" (Chanlat, 2021), sua relação com os pesquisadores brasileiros data dos anos 1980, na figura do professor Roberto Fachin, um dos criadores da ANPAD em 1976 (Fachin, 2006). Nos anos 1990, também em Montreal, Chanlat entra em contato com dois professores da FGV EAESP, Ofélia de Lana Torres e Fernando Prestes Motta, e com a professora Tania Fisher, da UFBA. A partir dos anos 1990, o contato de Chanlat é intenso com vários professores e pesquisadores no campo da Administração no País, com suas vindas ao Brasil e recebendo professores e alunos na Paris-Dauphine, com vários artigos e obras traduzidos para o português.

Além das memórias afetivas que o autor manteve e mantém com o País, Chanlat apresenta, nesse artigo, a história do pensamento francês no Brasil, que, no entanto, não se trata de uma via de mão única: de um lado, os autores franceses foram bem aceitos no País, mas a academia francesa também esteve aberta aos pensadores brasileiros. A visão antropofágica mostra que esse intercâmbio é intenso e, como destaca o autor, "uma alternativa à hegemonia anglo-saxã” no campo das Ciências Administrativas, que já vinha sendo criticada pelos autores brasileiros em Administração, como Motta e Caldas (1997), Caldas e Wood (1997), Motta, Alcadipani e Bresler (2001), entre outros. A busca de um pensamento original nas Ciências Administrativas no Brasil, destaca Chanlat, está presente desde Guerreiro Ramos, Mauricio Tragtenberg e Fernando Prestes Motta, autores que se destacam pelo pensamento crítico na academia brasileira de Administração (Paula, 2015). Chanlat (2021) destaca também autores contemporâneos críticos, como Alcadipani (2010), Alcadipani e Caldas (2012), Alcadipani e Rosa (2010) e Alcadipani e Faria (2014), entre outros. Seu artigo explora, ainda, diversos autores franceses que influenciaram fortemente as pesquisas brasileiras em Ergonomia e Psicodinâmica do Trabalho, em especial, o livro clássico de C. Dejours, “A loucura do trabalho”, publicado em português em 1987. Ler esse artigo de Chanlat é mergulhar, com afeto e alegria, na história mais recente da academia brasileira de Administração.

Na sequência dos artigos convidados, está o artigo da Editora-chefe da Revista de Administração Pública $(R A P)$ e atualmente Presidente da ANPAD, Alketa Peci, e sua coautora, Lilian Alfaia Monteiro, sobre o papel e o impacto dos periódicos acadêmicos em Administração no País. Cabe aqui um parêntese: Alketa Peci é a terceira mulher que ocupa a presidência dessa importante instituição no País, precedida apenas por Susana Braga Rodrigues, no biênio 1989-1990, e por Tânia Maria Diederichs Fischer, no biênio 1991-1992, ambas destacadas pesquisadoras no campo. Pode-se dizer que foram praticamente três décadas em que as mulheres, pesquisadoras ativas, fundantes do campo, estiveram ausentes da presidência da Associação, a mais importante em Administração no País. $O$ artigo de Paludi, Helms-Mills e Mills (2014) é bastante informativo sobre o desaparecimento da contribuição das mulheres não só nas corporações como também na academia em Administração, por suas práticas "genderizadas" que silenciam as vozes das mulheres na história do pensamento administrativo.

No artigo convidado "Revistas acadêmicas como agentes do campo científico de Administração", Peci e Monteiro (2021) mostram que a RAE, a RAP e RAUSP, antes praticamente hegemônicas no campo, passaram a 
conviver, nestas últimas décadas, com mais de 300 periódicos no campo da Administração. Um crescimento vertiginoso que as autoras destacam, mas sobre o qual não se conhece ainda "como esses atores se posicionam no campo científico da Administração e como, ainda, se diferenciam entre eles” (Peci \& Monteiro, 2021). As autoras mostram que o jogo do campo científico inclui lógicas, atores e regras de funcionamento. Com esse referencial, as autoras fazem uma análise longitudinal do campo dos Estudos Organizacionais no Brasil, a partir de artigos coletados desde os anos 1960 até 2014, na RAE, RAP e RAUSP. Apoiadas nesse levantamento, as autoras constroem diversas categorias para as estratégias de legitimidade da contribuição científica: o discurso científico interno, o discurso científico externo, o discurso da prática e o discurso da diferenciação, e destacam que o discurso científico interno e o discurso da prática "são as principais estratégias de legitimação historicamente utilizadas no campo" (Peci \& Monteiro, 2021, p. 8). No jogo do campo científico, a competição atinge também as revistas que precisam destacar-se nos rankings, dentro de uma lógica competitiva imposta por agentes como Coordenação de Aperfeiçoamento de Pessoal de Nível Superior (CAPES), Conselho Nacional de Desenvolvimento Científico e Tecnológico (CNPq) e programas de pós-graduação. Mas a lógica produtivista, ressaltam as autoras, nem sempre contribui para o fortalecimento do campo "em periódicos que são irrelevantes do ponto de vista científico" (Peci \& Monteiro, 2021, p. 13). Trata-se de uma questão fundamental, que será retomada na próxima seção, sobre os desafios futuros dos periódicos nacionais.

Num artigo autoral, profundo e delicado, Ana Paula Paes de Paula (2021) trata de sua relação pessoal com a revista: "Trintena: uma trajetória de vida, leitura e escrita com a RAE". Tal como exposto no artigo de Chanlat, o trabalho de Ana Paula mostra como os afetos se entremeiam com a construção da ciência. Nesse artigo, a autora descreve seu primeiro contato com a Revista, enquanto aluna do curso de Graduação no começo dos anos 1990, na Faculdade de Economia, Administração, Contabilidade e Atuária da Universidade de São Paulo (FEA-USP), depois como aluna do Mestrado em Administração Pública na FGV EAESP e, ainda, durante seu Doutoramento em Ciências Sociais, no Instituto de Filosofia e Ciências Humanas da Universidade de Campinas (IFCH-Unicamp). Ana Paula destaca os autores publicados na RAE, além de professores da FGV EAESP, que a influenciaram ao longo de sua trajetória acadêmica. Os artigos selecionados por Ana Paula são clássicos publicados na Revista: Maurício Tragtenberg (1971), em “A teoria geral da Administração é uma ideologia? "; Thomaz Wood Jr. (1992) em “Fordismo, toyotismo e volvismo: os caminhos da indústria em busca do tempo perdido"; Fernando Prestes Motta (1971, 1981, 1992) em: "Controle social nas organizações", “O poder disciplinar nas organizações formais" e "As empresas e a transmissão da ideologia”. A autora menciona também Wood e Caldas (1998) em "Antropofagia organizacional” e Wood (2000) em "Organizações de simbolismo intensivo". A partir dos anos 2000, Paula passa a integrar a lista de autores da RAE, com o artigo "Tragtenberg e a resistência da crítica: Pesquisa e ensino na Administração hoje" (Paula, 2001), quando se torna também avaliadora e editora associada da RAE. Nos anos 2000, Ana Paula fez seu Pós-Doutorado na FGV EAESP com orientação do professor Fernando Prestes Motta (e, quando do falecimento do saudoso professor, com o professor Peter Spink). Nesse período, em conjunto com o professor Thomaz Wood Jr., coordenou pesquisas sobre "pop-management” que resultaram em várias publicações. A trajetória da autora está marcada, como é possível observar, por diversos artigos publicados na RAE, por inúmeros projetos de pesquisa com os professores da FGV EAESP, além, claro, de sua própria e fecunda produção. Desde 2005 como professora na Faculdade de Ciências Econômicas da Universidade Federal de Minas Gerais (FACE-UFMG), Ana Paula destaca que a RAE esteve presente no seu aprender a ler e escrever numa perspectiva crítica, que marca a Revista desde sua origem. 
$O$ artigo que fecha esta edição especial traz um coletivo de mulheres, jovens integrantes da academia brasileira de Administração, com um texto que aponta para um futuro necessário. Juliana Cristina Teixeira, Josiane Silva de Oliveira, Ana Diniz e Mariana Mazzini Marcondes, pesquisadoras jovens, mas já reconhecidas, tratam de “Inclusão e diversidade na Administração: Manifesta para o futuro-presente”. Conforme aponta Bresser-Pereira (2021), de que vale a riqueza sem função social? 0 artigo das quatro autoras traz uma "manifesta" para que a pesquisa brasileira em Administração seja plural, inclusiva, representativa da diversidade geográfica e demográfica do País, em suas múltiplas dimensões, étnica, racial, etária e classe social, e que inclua processos de reparação para as desigualdades extremas do País. A perspectiva das autoras - duas mulheres negras e duas mulheres brancas - inclui, além das experiências pessoais, o aporte teórico da intersecionalidade, da decolonialidade e da transversalidade, com o objetivo claro de transformação social. 0 texto apresenta um breve histórico da "gestão" da diversidade que, embora disseminada, foi rapidamente transformada em consumo e discursos vazios. Cabe um parêntese nesse momento: no cenário brasileiro, o artigo seminal nesse campo foi escrito por Maria Tereza Leme Fleury e publicado na RAE em 2000, o que indica, mais uma vez, a abertura da Revista para tópicos emergentes e inovadores no campo da pesquisa em Administração.

Teixeira, Oliveira, Diniz e Marcondes (2021, p.5) destacam a necessidade de "repolitizar" o debate sobre diversidade e inclusão, para "a construção de um campo comprometido com o enfrentamento às desigualdades", estruturais na sociedade brasileira. Para isso, as autoras propõem uma "agenda de transformação", que inclui, necessariamente, uma mudança nas lógicas que operam as desigualdades, nos temas pesquisados e nos mecanismos que permitam a disseminação desses conhecimentos. Além disso, propõem as autoras, é preciso avançar na desconstrução das lógicas que organizam a "branquitude" e, consequentemente, naquilo que se considera como produtos científicos. A palavra diversidade, enquanto se pretenda inclusiva, é por demais generalizante para abarcar o diverso. Dar nomes aos bois pode ser perturbador, mas faz parte da mudança, já que a linguagem constrói a realidade.

Como é possível observar nos artigos apresentados, a criação e as contribuições pioneiras, críticas e sempre inovadoras da RAE são fundantes da história da Administração no Brasil, mas seus desafios futuros são imensos, como debatido a seguir.

\section{DESAFIOS FUTUROS DA RAE (E DOS PERIÓDICOS BRASILEIROS)}

A RAE, em seu papel de destaque no cenário nacional de produção e disseminação do conhecimento, enfrenta o desafio de se internacionalizar, não apenas para expandir sua capacidade de dialogar com o mundo, mas também por conta do que representa em termos de pioneirismo e relevância. 0 desafio é particularmente complexo para um periódico que contribuiu para a construção do conhecimento no País no campo aplicado e acadêmico, e para a construção da profissão em Administração e, consequentemente, para o desenvolvimento do País e sua visão de mundo no contexto sociopolítico (Tonelli \& Zambaldi, 2017). A revista foi publicada predominantemente em português ao longo de quase cinco décadas, período em que certamente se beneficiou da liberdade de privilegiar uma agenda de pesquisa com objetos relevantes no contexto nacional. A possibilidade de construir uma história e um legado em português conferiu autonomia ao periódico, tendo em vista que a hegemonia da produção em inglês pode seguir uma lógica colonial controladora dos critérios de publicação e circulação e da definição do que é qualidade (Rosa \& Alves, 2011). 
A intensificação por parte da CAPES de critérios de avaliação de periódicos com enfoque no impacto calculado por indexadores internacionais levou a RAE a buscar sua indexação em tais bases no final dos anos 2000 , tendo como resultado sua inserção em coleções como Journal Citation Reports (JCR) e Scopus. Soma-se a esse movimento a orientação dos principais programas de pós-graduação na área e de escolas de negócios no Brasil a intensificarem sua inserção no contexto internacional sob as mesmas premissas. Concomitantemente, outros periódicos brasileiros também se movimentaram rumo à internacionalização, e outros nasceram já com a prerrogativa de publicar todos os seus artigos em inglês na primeira metade dos anos 2000. Embora tal movimento tenha permitido atingir públicos mais amplos, a barreira da língua é uma dificuldade para uma comunidade que não foi educada em inglês em sua formação de pesquisa, como explica Farias (2017). Em uma abordagem mais crítica, Alcadipani (2017) alerta para os riscos dos esforços de internacionalização de nossos periódicos em termos de submissão ao publish or perish anglo-saxão, com restrições aos padrões de inglês adotados na comunicação dos eixos dominantes, assim como seus temas e abordagens, caracterizando o que classifica como provincianismo global e colonialismo epistêmico.

Os produtos dos esforços da academia brasileira em Administração para se internacionalizar levaram ao aumento da produção de pesquisadores brasileiros e da presença de nossos periódicos no cenário global, mas também forjaram de alguma forma a padronização de temas e métodos em nossas escolhas de pesquisa, com maior grau de mimetização do que é publicado no que costumamos classificar como top journals, porém agravada por algum atraso que enfrentamos para tomar contato com o que se pesquisa nos centros com mais fácil acesso a esses periódicos qualificados como de ponta. Como caracterizado por Peci e Monteiro (2021), a internacionalização da produção e dos periódicos brasileiros em Administração é um novo capital simbólico de diferenciação de revistas e artigos, em um jogo concentrado em referências preexistentes dentro dos campos de estudo como estratégia de legitimação - o chamado Discurso Científico Interno (DCI), com pouco espaço para a assimilação crítica ou adaptação de teorias estrangeiras à realidade nacional como alternativas a aplicações diretas de modelos estrangeiros.

De toda forma, Diniz (2017), que atuou como Editor-chefe da RAE por sete anos, considera o processo de internacionalização da produção e dos periódicos brasileiros inexorável, alertando para a necessidade de não permanecermos como expectadores das transformações no mundo da pesquisa e de desenvolvermos estratégias e políticas institucionais próprias de posicionamento dos periódicos nacionais na internacionalização, de modo a não serem diminuídos em relação a periódicos estrangeiros por conta de serem nacionais. A indexação da RAE em bases internacionalmente reconhecidas e o aumento das publicações de seus artigos em outros idiomas geraram notórios avanços na exposição da revista à academia em Administração para além do Brasil, e certamente em sua atratividade para submissões de autores de outros países. Uma evidência é o fato de termos atualmente um contingente superior a $20 \%$ do total de submissões que contam com autores afiliados a instituições no exterior, com boa distribuição entre os continentes. Entre as iniciativas realizadas e resultados obtidos pela revista, destacam-se a disponibilização trilíngue do website, a adoção de uma plataforma mundial de submissão de artigos, chamadas internacionais de trabalhos, publicação de artigos em três idiomas, a ampliação da participação de membros de instituições estrangeiras no corpo editorial, o aumento de citações em bases indexadas e o crescimento da proporção de artigos em língua estrangeira (Tonelli \& Zambaldi, 2017). Todavia, fatores como o histórico de publicações predominantemente em português e a escassez de periódicos brasileiros indexados em bases internacionais - periódicos esses que ainda são a maior fonte de citações da revista - inibem 
o incremento dos indicadores do impacto da $R A E$ nas bases tidas como principais em comparação a outros periódicos também nelas indexados. Tais fatores dificultam sua inclusão em listas de periódicos valorizados como publicações de excelência nos eixos dominantes na academia mundial, tais como as listas Australian Business Deans Council (ABDC) e Academic Journal Guide, Association of Business School (AGJ/ABS) e, consequentemente, são obstáculos para a atratividade de periódicos em situação comparável em receber submissões e citações.

O modelo de contratação e evolução na carreira de pesquisadores adotado pelas escolas de negócios mais proeminentes no mundo os incentiva - sobretudo aqueles em início de carreira - a mirar muito mais os periódicos com maiores indicadores de impacto dentro dos critérios dominantes, ou os que foram incluídos em listas de acesso restrito, reforçando e perpetuando seus processos de avaliação já excludentes. Os pesquisadores estão cientes das consequências, mas reagem, muitas vezes, com resignação e demonstram pouca disposição a promover mudanças, limitando-se a culpar o sistema e entidades externas, conforme relatado por Machado e Bianchetti (2011). Os autores alertam para a restrição de temas estudados e a consequente limitação da autonomia universitária e alienação dos pesquisadores em relação ao processo que os restringe e conduz.

A manutenção das dinâmicas aqui descritas resulta no alijamento ainda maior de periódicos que construíram relevância local e desenvolveram capacidades de diálogo com stakeholders regionais. Assim, publicações, muitas vezes, abrem mão de suas capacidades distintivas em níveis locais para aproximarem suas práticas do que é feito nas chamadas publicações de referência, mesmo longe de estarem em condições de igualdade de competição. Consequentemente, o processo de internacionalização de periódicos, mesmo que traga vantagens de visibilidade e diálogo com um universo mais amplo, além de oportunidades de benchmarking, é também desigual e, de certa forma, inibe os potenciais de construção e manutenção da identidade dos periódicos considerados periféricos. Um estudo de Favaretto e Francisco (2017) com o acervo da RAE até sua data de publicação mostra a predominância de autores individuais no início de sua existência até a inflexão para os estudos com múltiplos autores (mais comumente três) nas publicações mais recentes, contemplando os benefícios e aprendizados provenientes das colaborações entre pares. Mas a longa fase caracterizada pelos trabalhos com apenas um autor foi também marcada pela vasta quantidade de textos de autores que, de alguma forma, se tornaram os expoentes do pensamento brasileiro em Administração e áreas correlatas, e, à medida que se tornaram menos frequentes, deram brecha a uma espécie de abdicação da identidade nacional da revista ao diminuir o espaço desses expoentes, mesmo que de modo não intencional, e mesmo que a vasta maioria da produção publicada na revista continue sendo realizada por autores brasileiros. É como ter um canal de divulgação de pesquisa realizada predominantemente por autores nacionais, visível e acessível ao exterior, mas perdendo parte da distinção de ser um canal de divulgação de um pensamento nacional.

As tendências de padronização das práticas adotadas em periódicos para atrair submissões, avaliar trabalhos e distribuir conteúdos são acompanhadas pela implementação em larga escala de sistemas únicos de informação e comunicação pela academia mundo afora, tais como o Digital Object Indentifier (DOI) para artigos e textos em geral, o Open Researcher and Contributor ID (ORCID) para pesquisadores e o Research Organization Registry (ROR) para instituições. Tais sistemas têm o potencial de armazenar e disponibilizar informações ampla e rapidamente, conectar as comunidades de pesquisa, viabilizar buscas e prover registros íntegros em diversas plataformas no meio acadêmico, configurando benefícios claros. Seu potencial, entretanto, pode ser cooptado pelas regras vigentes responsáveis pelo desequilíbrio entre periódicos ou mesmo entre centros de pesquisa no que se refere à valorização da pesquisa produzida e disseminada. A discussão passa pela definição de quais são 
os periódicos merecedores de reconhecimento global até a definição dos meios de distribuição que são desejáveis e merecem eventualmente mais reconhecimento por parte da comunidade acadêmica.

Para além das ameaças às questões identitárias e à relevância regional de periódicos em contextos periféricos no sistema de avaliação predominante, há um contingente de pesquisadores espalhados pelo globo que demonstra desconforto e requer ampliações dos critérios pelos quais os resultados da pesquisa acadêmica e os próprios pesquisadores são avaliados. Tal demanda pode ser exemplificada pela Declaration on Research Assessment (DORA), que se caracteriza como um movimento abrangente de todos os campos do conhecimento com participação de diversos stakeholders entre patrocinadores, editoras e instituições de ensino e pesquisa, além de pesquisadores em si. 0 movimento não se opõe aos sistemas integrados de armazenamento e disseminação do conhecimento e sua consequente padronização, mas anseia por maior abrangência de meios reconhecidos como meritórios da disseminação da pesquisa, tanto em quantidade como em forma. A demanda permite vislumbrar que, uma vez que pesquisadores possam ser reconhecidos e recompensados por suas instituições por divulgarem seus resultados de pesquisa em canais complementares ou alternativos aos periódicos conhecidos como de ponta, podem ter mais liberdade para acessarem temas relevantes e um público mais extenso, com maior propriedade sobre a disseminação de suas pesquisas. 0 resultante potencial para o incremento do impacto social da pesquisa por conta da capacidade e qualidade aprimorada de diálogo com diversos interlocutores na sociedade é promissor.

A RAE paticipou do terceiro Webinar on Management Research Publications da International Federation of Scholarly Associations of Management (IFSAM) ${ }^{\star \star}$, realizado recentemente com a presença on-line de pesquisadores, editores e instituições de ensino e pesquisa de diversos países. 0 encontro reforçou o anseio da comunidade de pesquisa em Gestão para que formatos para além do artigo acadêmico, tais como livros, casos de ensino e até produtos audiovisuais e apresentações, sejam valorizados e incentivados como produtos de pesquisa, de modo a dar mais liberdade para pesquisadores nas escolhas dos meios de publicação que possam gerar maior alcance e diversidade de público. Embora seja essa uma reivindicação crescente entre pesquisadores, tomadores de decisão nas instituições de ensino acerca das balizas determinantes do que é bom desempenho em pesquisa concentram seus critérios no modelo baseado em impactos dos top journals, o que retarda o crescimento de periódicos com menor impacto nos indexadores do mainstream, considerando-se o tempo que leva para uma publicação obter um índice de impacto avaliado como alto em tais bases. Uma potencial mudança de rumo pode ser fomentada, no entanto, por eventuais iniciativas de acreditadores relevantes para escolas de negócios de avaliar a produção de conhecimento também por seu impacto social, como a EFMD tem sinalizado (EFMD/BSIS, 2020).

O requerimento por mais amplitude de canais de disseminação da pesquisa em Gestão não exclui os periódicos científicos, evidentemente, mas defende menor concentração em periódicos entre os classificados como de ponta pelos critérios dominantes e maior valorização dos periódicos de nicho, importantes para grupos específicos que produzem e consomem pesquisa com algum grau de especificidade, porém dotada de relevância para diversos stakeholders. Nesse grupo, periódicos com histórico impacto regional, como a RAE, embora generalistas, também se enquadram e teriam mais reconhecimento ao se concentrarem em questões aderentes ao ambiente em que estão inseridos, como desafios presentes em nações emergentes e aspectos culturais específicos da Administração concernentes a objetos de interesse global por conta de particularidades e riquezas de seus contextos. 0 resultado poderia ser a redução da mimetização das práticas adotadas pelos periódicos 
líderes no que se refere a seleção de temas e priorização de métodos específicos nos processos de avaliação, conferindo-lhes uma relevância mais genuína no cenário internacional, menos a reboque das tendências trazidas pelas publicações de referência global mais hegemônicas.

O webinar da IFSAM também revelou que a quantidade de submissões de artigos ao redor do mundo aumentou nos periódicos em geral, assim como ocorreu com a $R A E$, e que temas envolvendo questões como igualdade de gênero e responsabilidade social têm sido recorrentes e crescentes nas submissões aos periódicos da área. Essas podem ser evidências de que pesquisadores, em toda parte, estão comprometidos com o impacto social de suas pesquisas, como os Objetivos de Desenvolvimento Sustentável da ONU (2021), por exemplo, algo que pode ter sido intensificado com o momento delicado que vivemos mundialmente nas esferas econômica e social, impactadas fortemente pela pandemia. Nesse sentido, a questão da divulgação de resultados de pesquisa para uma sociedade interessada e afetada pelos objetos de estudo da Administração é premente, especialmente no que tange a alcançar aqueles que podem ser os agentes de implantação de resultados de pesquisa relevantes, os chamados praticantes da Gestão em diversos tipos de organizações.

O formato superespecializado da produção e redação da pesquisa publicada em periódicos é um desafio antigo na academia, intensificado pela ênfase no rigor teórico e metodológico e suas formas de comunicação. 0 problema é mundial e cresceu no Brasil com a adoção de regras e práticas instituídas e incentivadas por entidades de regulação e incentivo à pesquisa, muito fortemente desde o final da década de 1990 (Bertero, 2006c), pois a forma de fazer e comunicar pesquisa ficou circunscrita aos pesquisadores acadêmicos, e, consequentemente, a leitura de seus resultados também. A própria trajetória da RAE como revista e sua transição para um periódico mais alinhado às práticas globalmente reconhecidas da publicação acadêmica até o final dos anos 2000 evidencia isso (Mascarenhas, Zambaldi, \& Moraes, 2011). Como ilustração, uma análise de mineração de texto do acervo completo da RAE-eletrônica de 2002 a 2010 realizado por Francisco (2011) evidencia que, nessa década de transição e aceleração da adoção de práticas mais populares entre publicações internacionais, as principais referências citadas nos artigos foram provenientes, além da própria RAE e dos encontros da ANPAD, de periódicos internacionais. Adicionalmente, os autores que mais publicaram no período eram afiliados aos programas de pós-graduação com melhor avaliação por parte da CAPES.

Uma questão pertinente e recorrente é se os periódicos devem se consolidar como meio de comunicação superespecializado e restrito a um grupo de acadêmicos pesquisadores, se é que já não se consolidaram como tal, e se as pesquisas tenham que ter formatos de entrega adicionais em outros meios, como livros, textos em mídias de circulação em massa e materiais audiovisuais e digitais sumarizados. Cada pesquisa teria de ter uma versão de divulgação orientada aos periódicos científicos, selando seu rigor e qualidade, e ao menos uma outra versão orientada ao praticante e à sociedade em geral. Essa alternativa é discutível em termos de volume e viabilidade, e mesmo de potenciais resultados, mas certamente interessa aos periódicos científicos que pretendam ter reconhecimento para além da academia. Um exemplo é o fato de publishers permitirem que seus autores também divulguem em suas bases de comunicação apresentações sucintas e mais palatáveis aos praticantes ou mesmo representações gráficas de seus artigos. Não é impossível que tais versões no futuro possam até ser obrigatórias para acompanhar a publicação em periódicos. Seus resultados em termos de impacto no ambiente da prática, no entanto, ainda são subavaliados e desconhecidos.

É um fato, contudo, que pesquisadores em Administração lidam com problemas reais das organizações e trabalham com rigor, mas desovam seus achados em meios pouco frequentados pelos praticantes. Um caminho 
pode ser a inclusão dos praticantes nas iniciativas de pesquisa e sua execução, em processos de cocriação, de modo que não sejam tratados apenas como provedores de acesso ao campo ou fontes de informação, e possam trazer contribuições em relação ao que se pesquisa e como se pesquisa por estarem inseridos no processo (Mascarenhas et al., 2011). Talvez assim possam reconhecer o valor da pesquisa mais naturalmente e fazer uso mais intenso e efetivo de seus produtos. Tal alternativa pode ser um caminho natural de alinhamento a iniciativas de escolas de negócios em oferecer programas de formação em pesquisa com ênfase profissional, realizada por praticantes da Gestão, crescentes em centros reconhecidos em ensino e pesquisa, inclusive no Brasil, observados com a proliferação de programas de mestrado e até de doutoramento profissionais.

Como se observa, os desafios não são poucos nem simples para o futuro de uma revista como a RAE e a comunidade ao seu entorno, com um histórico de relevância local, porém com desvantagens competitivas na inserção internacional sob os parâmetros globais predominantes de avaliação da pesquisa e seus incentivos consequentes aos pesquisadores. Lidar com tais desafios requer investimento e trabalho colaborativo diante das oportunidades que também se abrem. Nesse contexto, é difícil para um periódico mantido por uma escola de negócios ser competitivo em um mercado em que publishers profissionais são predominantes. É necessário reforçar aqui que essa situação se estende à maior parte dos periódicos da área no Brasil, pois costumam ser vinculados e sustentados por programas de pós-graduação (Alencar, 2017). As editoras contam com equipes profissionais, ganhos de escala e economia, prestígio e competências únicas. Mais do que isso, beneficiam-se de um modelo de negócio em que autores produzem conteúdo com rigor e servem como avaliadores para garantir a qualidade do que seus pares produzem, mas não se beneficiam monetariamente do sistema por não serem remunerados nem poderem acessar os conteúdos sem que tenham que pagar por isso (ou suas instituições tenham que pagar). Esse é um ponto de desconforto para muitos pesquisadores, embora as editoras estejam cientes e já participem de discussões e inciativas que visam a proporcionar uma relação de maior equidade em termos de contribuição e recompensa. Uma dessas iniciativas é o crescimento livre e aberto dos conteúdos de pesquisa (Diniz, 2017), que, no entanto, muitas vezes esbarra em aspectos de qualidade e onera autores ou instituições proprietárias para que viabilizem os custos de publicação (Alencar, 2017). Nesse cenário, periódicos que não contem com estrutura ampla profissional de um grupo editorial enfrentarão cada vez mais dificuldades de se sustentarem no médio e longo prazos, assim como pesquisadores inseridos em instituições e contextos com limitadas disponibilidades de recursos monetários.

\section{PARA FINALIZAR}

Na sua trajetória, a RAE foi uma estrela solitária, e a alta meia-vida de seus artigos tem duas faces: de um lado, mostra a importância de artigos e autores clássicos que têm sido reiteradamente citados, mas, de outro, essas citações não são contempladas no cálculo de fator de impacto pelos indexadores internacionais. É o preço a pagar por essa trajetória de décadas. Além disso, como mostramos nas seções anteriores, a RAE, como alguns outros periódicos nacionais, sofre por falta de identidade e pela dificuldade de inserção no debate científico internacional. Outro aspecto que cabe destacar é que se a $R A E$, na sua trajetória, teve autores solitários, o futuro da pesquisa pede, cada vez mais, a participação de uma coletividade representada, nesta edição, por um grupo de mulheres negras e mulheres brancas, para destacar, várias vezes esquecida, a representatividade demográfica e racial do País. Ao longo de sua trajetória, podemos comemorar que a RAE se tornou mais colaborativa. 
Ao se abrir mais para o mundo, dada a aceleração de seu processo de internacionalização, a $R A E$, junto com a produção brasileira na área como um todo, passou a ser vista por um universo maior, o que certamente é facilitado pelo modelo adotado de acesso aberto a todo seu acervo em conjunto com os processos de indexação e comunicação e publicação em outros idiomas. Mesmo que com isso tenha cedido parte de sua identidade como um espaço de construção e disseminação de um pensamento nacional em Administração, poderá seguir seu caminho sem abrir mão de uma vocação orientada ao impacto social e à contribuição em demandas como redução de desigualdades diversas, sustentabilidade ambiental e social, inclusão social e desenvolvimento socioeconômico. Tais temas são crescentemente abordados por pesquisadores e editores diversos na academia mundial, sejam de eixos hegemônicos ou não, e, com isso, há oportunidade para a RAE e outras publicações ao seu entorno assumirem a responsabilidade de capitanear, em parte, essas transformações no contexto da publicação acadêmica. As consequências do período pandêmico que vivemos, muitas delas ainda desconhecidas, legitimam e fomentam esse caminho e são oportunidades para a revista fortalecer seu posicionamento rumo à pavimentação de um mundo mais inclusivo e consciente no campo da Gestão.

O caminho não é solitário, e nem deve ser, pois requer interlocução com outros agentes como editoras, patrocinadores, instituições de ensino e pesquisa, a comunidade de pesquisadores, indexadores, órgãos reguladores, acreditadores e outros periódicos. Entre pesquisadores, a inclusão dos praticantes da Gestão como cocriadores e legitimadores do processo de pesquisa e publicação é importante para garantir e expandir a relevância dos artigos e sua integração com os crescentes programas profissionais de formação em pesquisa. Em relação ao suporte das instituições de ensino, só será possível vislumbrar um caminho de maior impacto social na publicação em Administração se tais instituições e seus programas de pós-graduação abraçarem uma diversidade maior de periódicos e meios de comunicação que se comprometam com tal impacto. E isso também depende do suporte de órgãos reguladores da pesquisa em âmbito nacional. Caso contrário, os esforços de unificação e padronização da informação acerca de pesquisas, instituições e autores será enviesado e correrá o risco de recrudescer a perpetuar as desigualdades de condições entre as publicações que são líderes globais daquelas que as seguem. A redução dessas desigualdades pode ser encampada como uma bandeira da RAE e de periódicos brasileiros, valendo-se de ventos favoráveis como os Objetivos de Desenvolvimento Sustentável da ONU, o movimento DORA e a potencialidade de avaliação do impacto social das instituições e seus programas por parte de entidades acreditadoras. Mas contar com que esses ventos favoráveis façam o trabalho sozinhos seria uma ilusão, portanto há um longo trabalho de protagonismo pela frente.

Ao longo de suas décadas, a RAE foi pioneira, capaz de se reinventar, de propor inovações. Os artigos convidados deste especial mostram sua força e seu papel inestimável na construção da Academia Brasileira em Administração de Empresas. Vida longa à Revista e que ela possa celebrar, num futuro nem tão distante, 120 anos.

\section{NOTAS DOS AUTORES}

* Manifestamos nossos profundos sentimentos por tantas perdas e danos experimentados não só na comunidade acadêmica em Administração como no País.

** Agradecemos a Xavier Castañer, do IFSAM, e Alketa Peci, da ANPAD, a oportunidade. 


\section{REFERÊNCIAS}

Alcadipani, R. (2010). Critical international management and international critical management: Perspectives from Latin America. Critical Perspectives on International Business, 6(2/3). doi: 10.1108/cpoib.2010.29006baa.001

Alcadipani, R. (2017). Periódicos brasileiros em inglês: A mímica do publish or perish "global". RAE-Revista de Administração de Empresas, 57(4), 405-411. doi: 10.1590/s0034-759020170410

Alcadipani, R., \& Bertero, C. O. (2012). Guerra Fria e ensino do management no Brasil: 0 caso da FGV-EAESP. RAE-Revista de Administração de Empresas, 52(3), 284-299. doi: 10.1590/ So034-75902012000300002

Alcadipani, R., \& Caldas, M. P. (2012). Americanizing Brazilian management. Critical Perspectives On International Business, 8(1), 37-55. doi: 10.1108/17422041211197558

Alcadipani, R., \& Faria, A. (2014). Fighting Latin American marginality in "international" business". Critical Perspectives on International Business, 10(1/2), 107-117. doi: 10.1108/ cpoib-11-2013-0047

Alcadipani, R., \& Rosa, A. R. (2010). The researcher as the other: A postcolonial reading of the Brazilian "Borat". RAE-Revista de Administração de Empresas, 50(4), 371-382. 10.1590/So03475902010000400003

Bertero, C. O. (1968). Algumas observações sobre a obra de G. Elton Mayo. RAE-Revista de Administração de Empresas, 8(27), 73-95. doi: 10.1590/So034-75901968000200003

Bertero, C. O. (2006a). Editorial. RAE-Revista de Administração de Empresas, 46(2), 5. doi:10.1590/S0034-75902006000200001

Bertero, C. O. (2006b). A RAE nos seus 45 anos. RAE-Revista de Administração de Empresas, 46(2), 114-117. doi: 10.1590/ So034-75902006000200008

Bertero, C. O. (2006c). Ensino e pesquisa em administração. São Paulo, SP: Thomson Learning.

Bertero, C. O. (2011). Meio século de RAE. RAE-Revista de Administração de Empresas, 51(3), 224-226. doi: 10.1590/ So034-75902011000300002

Bertero, C. O. (2021). Sessenta anos de RAE: Um itinerário de críticas, resistências e reinvenções. RAE-Revista de Administração de Empresas, 61(3), eoooo-0011. doi: 10.1590/ So034-759020210303

Bertero, C. O., \& Keinert, T. M. M. (1994). A evolução da análise organizacional no Brasil (1961-93). RAE-Revista de Administração de Empresas, 34(3), 81-90. doi: 10.1590/ So034-75901994000300007

Bertero, C. O., Vasconcelos, F. C. D., Binder, M. P., \& Wood, T., Jr. (2013). Produção científica brasileira em administração na década de 2000. RAE-Revista de Administração de Empresas, 53(1), 12-20. doi: 10.1590/So034-75902013000100002
Bresser-Pereira, L. C. (1962a). The rise of middle-class and middle management in Brazil. Journal of Inter-American Studies, 4(3), 313-326. doi: 10.2307/164949

Bresser-Pereira, L. C. (1962b). Desenvolvimento econômico e o empresário. RAE-Revista de Administração de Empresas, 2(4), 79-91. Recuperado de http://bibliotecadigital.fgv.br/ojs/ index.php/rae/article/view/38445

Bresser-Pereira, L. C. (1966). O administrador profissional e as perspectivas da sociedade brasileira. RAE-Revista de Administração de Empresas, 6(20), 89-110. doi: 10.1590/ So034-75901966000300004

Bresser-Pereira, L. C. (2021). Depois do capitalismo, o gerencialismo democrático. RAE-Revista de Administração de Empresas, 61(3), e0000-0012. doi: 10.1590/So034759020210304

Caldas, M. P., \& Wood, T., Jr. (1997). Identidade organizacional. RAE-Revista de Administração de Empresas, 37(1), 6-17. doi: 10.1590/S0034-75901997000100002

Caldas, M. P., \& Wood, T., Jr. (2000). Fads and fashions in management: The case of ERP. RAE-Revista de Administração de Empresas, 40(3), 8-17. doi: 10.1590/So03475902000000300002

Chanlat, J.-F. (2021). Influência de pensamento de língua francesa na academia brasileira de administração: Um olhar francoquebequense. RAE-Revista de Administração de Empresas, 61(3), e0000-0013. doi: 10.1590/So034-759020210305

Diniz, E. H. (2017). Periódicos brasileiros da área de administração no contexto de internacionalização da produção científica. RAE-Revista de Administração de Empresas, 57(4), 357-364. doi: $10.1590 /$ so034-759020170406

EFMD Global services/ Business School Impact System (2020). Business School Impact System/Assessment criteria guide. Recuperado de efmdglobal.org/bsis - fnege.org/nosprogrammes/bsis

Fachin, R. C. (2006). Construindo uma associação científica: Trinta anos de ANPAD - memórias, registros, desafios. Porto Alegre, RS: ANPAD.

Farias, S. A. D. (2017). Internacionalização dos periódicos brasileiros. RAE-Revista de Administração de Empresas, 57(4), 401-404. doi: 10.1590/s0034-759020170409

Favaretto, J. E. R., \& Francisco, E. D. R. (2017). Exploração do acervo da RAE-Revista de Administração de Empresas (de 1961 a 2016) à luz da bibliometria, text mining, rede social e geoanálise. RAE-Revista de Administração de Empresas, 57(4), 365-39o. doi: 10.1590/s0034-759020170407

Francisco, E. D. R. (2011). RAE-eletrônica: Exploração do acervo à luz da bibliometria, geoanálise e redes sociais. RAE-Revista de Administração de Empresas, 51(3), 280-306. doi: 10.1590/ So034-75902011000300008 
Machado, A. M. N., \& Bianchetti, L. (2011). (Des)fetichização do produtivismo acadêmico: Desafios para o trabalhadorpesquisador. RAE-Revista de Administração de Empresas, 51(3), 244-254. doi: 10.1590/So034-75902011000300005

Mascarenhas, A. O., Zambaldi, F., \& Moraes, E. A. D. (2011). Rigor, relevância e desafios da academia em administração: Tensões entre pesquisa e formação profissional. RAE-Revista de Administração de Empresas, 51(3), 265-279. doi: 10.1590/ So034-75902011000300007

Motta, F. C. P. (1971). A teoria geral dos sistemas na teoria das organizações. RAE-Revista de Administração de Empresas, 11(1), 17-33. doi: 10.1590/So034-75901971000100003

Motta, F. C. P. (1981). O poder disciplinar nas organizações formais. RAE-Revista de Administração de Empresas, 21(4), 33-41. doi: 10.1590/So034-75901981000400003

Motta, F. C. P. (1992). As empresas e a transmissão da ideologia. RAE-Revista de Administração de Empresas, 32(5), 38-47. doi: /10.1590/S0034-75901984000300004

MOTTA, F. P. (1979). Controle social nas organizações. RAERevista de Administração de Empresas, 19(3), 11-25. doi: 10.1590/So034-75901979000300002

MOTTA, F. P., \& CALDAS, M. (1997). Cultura organizacional e cultura brasileira. São Paulo: Atlas, 1997.

Motta, F. C. P., Alcadipani, R., \& Bresler, R. B. (2001). A valorização do estrangeiro como segregação nas organizações. Revista de Administração Contemporânea, 5(SPE), 59-79. doi: 10.1590/ S1415-65552001000500004

Organização das Nações Unidas Brasil. (2021, março). Sobre o nosso trabalho para alcançar os Objetivos de Desenvolvimento Sustentável no Brasil. Recuperado de https://brasil.un.org/ $\mathrm{pt}-\mathrm{br} / \mathrm{sdgs}$

Paludi, M., Helms-Mills, J., \& Mills, A. J. (2014). Disturbing thoughts and gendered practices: A discursive review of feminist organizational analysis. In S. Kumra, R. Simpson, \& R. J. Burke, The Oxford handbook of gender in organizations. Oxford: Oxford Press.

Paula, A. P. P. de. (2001). Tratenberg e a resistência crítica: Pesquisa e ensino em administração hoje. RAE-Revista de Administração de Empresas, 41(3), 77-81. doi: 10.1590/ So034-75902001000300010

Paula, A. P. P. de. (2015). Estudos organizacionais críticos e pensadores nacionais. Cadernos EBAPE.BR, 13(3), 410-413. Recuperado de http://bibliotecadigital.fgv.br/ojs/index. $\mathrm{php/cadernosebape/article/view/49070}$
Paula, A. P. P. de. (2021). Trintena: Uma trajetória de vida, leitura e escrita com a RAE. RAE-Revista de Administração de Empresas, 61(3), e0000-0015. doi: 10.1590/S0034-759020210307

Peci, A., \& Monteiro, L. A. (2021). Revistas acadêmicas como agentes do campo científico de administração. RAE-Revista de Administração de Empresas, 61(3), eoooo-0014. doi: 10.1590/So034-759020210307

Rosa, A. R., \& Alves, M. A. (2011). Pode o conhecimento em gestão e organização falar português? RAE-Revista de Administração de Empresas, 51(3), 255-264. doi: 10.1590/ So034-75902011000300006

Teixeira, J. C., Oliveira, J. S, Diniz, A., \& Marcondes, M. M. (2021). Inclusão e diversidade na administração: Manifesta para o futuro-presente. RAE-Revista de Administração de Empresas, 61(3), e0000-0016. doi: 10.1590/So034-759020210308

Tonelli, M. J. (2017) The foundation of the academic field in business and administration in Brazil: The case of RAUSP. RAUSP-Management Journal, 52(4), 359-362. doi: 10.1016/j. rausp.2017.08.001

Tonelli, M. J. (2018). Revistas científicas sobre administración: El papel histórico de la RAE-Revista de Administração de Empresas (RAE) en la construcción del campo académico de la administración en Brasil. Cadernos EBAPE. BR, 16(spe), 509-515. doi: 10.1590/1679-395173941

Tonelli, M. J. \& Zambaldi, F. (2017). Editorial. RAE-Revista de Administração de Empresas, 57(4), 1-2. doi: 10.1590/s0034759020170401

Tragtenberg, M. (1971). A teoria geral da administração é uma ideologia? RAE-Revista de Administração de Empresas, 11(4), 7-21. doi: 10.1590/So034-75901971000400001

Valente, R., \& Serafim, M. C. (2006). RAE 45 anos: recortes de sua história. RAE-Revista de Administração de Empresas, 46(2), 104-111. doi: 10.1590/So034-75902006000200007

Wood, T., Jr. (1992). Fordismo, toyotismo e volvismo: Os caminhos da indústria em busca do tempo perdido. RAE-Revista de Administração de Empresas, 32(4), 6-18. doi: 10.159o/So03475901992000400002

Wood, T., Jr. (2000). Organizações de simbolismo intensivo. RAE-Revista de Administração de Empresas, 40(1), 20-28. doi: $10.1590 /$ So034-75902000000100003

Wood, T., Jr., \& Caldas, M. P. (1998). Antropofagia organizacional. RAE-Revista de Administração de Empresas, 38(4), 6-17. doi: $10.1590 /$ So034-75901998000400002

\section{CONTRIBUIÇÃO DOS AUTORES}

Os autores declaram que tiveram contribuição de forma conjunta no desenvolvimento do texto. Desde a conceitualização e abordagem teórica-metodológica, revisão teórica (levantamento de literatura), redação e revisão final do manuscrito. 